\title{
Enhancing Relevance In Education Through A Contextually Designed Curriculum
}

\author{
Rosemary Mbogo \\ School of Education, Arts and Social Sciences \\ Africa International University \\ Mellitus N. Wanyama \\ School of Music and Performing Arts \\ Kabarak University \\ P.O. Box Private Bag 20157 Kabarak
}

\begin{abstract}
The ever-changing needs of students, teachers and other education stakeholders as well as the needs in the job market necessitates having a responsive curriculum that bridges the knowledge gap and contextual realities of the world today. Despite the widely acknowledged importance of a contextually relevant curriculum design, its implementation remains a challenge in many learning institutions in Kenya. This paper is a review on designing a contextual curriculum that is relevant to the education system in Kenya. The paper thus explores the development of a contextually relevant curriculum (CRC); identifying various contextual considerations for its design, explaining the dynamics in developing $\mathrm{CRC}$, and describing the how to develop and evaluate a CRC.
\end{abstract}

Key words: Relevant, Contextual, Curriculum design, Curriculum evaluation, Change.

\section{INTRODUCTION}

Curriculum has been defined by various scholars but its definition remains hardly conclusive. Among these scholars are Pillai (2015) who considers curriculum as comprising all the experiences undergone by a learner in a particular institution and looks at curriculum as a means to achieve particular educational goals. He adds that curriculum is a comprehensive plan for an educational programme aimed at offering improved manpower to fulfil the rising needs of the dynamic society in which we live. Schrewe et al. (2018) popularises curriculum as the master plan for choice of content and the organisation of learning experiences with an aim of changing the learners' behaviours and insights, and that curriculum is a means by which educational goals and objectives are achieved ( $\mathrm{Su}, 2012)$. In essence, all these scholars agree that curriculum is a body of knowledge, a product to achieve certain ends and a process of interaction. Thus, curriculum plays a key role in both individual and societal development.

The acquisition of knowledge, skills and attitudes both for personal and societal development is a result of a well-developed curriculum. In Kenya, the development of the curriculum for all educational levels is a mandate of the Kenya Institute of Curriculum Development (KICD) (KICD Act, 2013). Education is considered the most fundamental tool in any economy's development and for intellectually built successive generations (Ozturk, 2008). The sustainable development goal (SDG 4) puts its emphasis in attaining quality universal education. The UN (2006) also reiterated, in Kenya's vision 2030, the attainment of free and compulsory basic education through Education for all (EFA) (RoK, 2013). Chiriswa and Thinguri (2015) 
recognize the role played by the secondary education curriculum in promotion of national unity, embracing diversity, and creating an internationally conscious and sustainable economy. The Dar-es-Salaam-Declaration in 2010 pointed to the obsolescence of the higher education curricula due to the increasingly dynamic environment in the world's economy and across all sectors. This consequently leads to a growing gap between education theory and societal reality that individuals face when exposed to a working environment. Transformation of students from assimilation to transfer of knowledge is therefore key in ensuring that institutions of learning remain relevant based on a contextually relevant curriculum. Donald Schön in Neumann (2000) places a remarkable emphasis on curriculum design that learning should be contextualised. He describes learning as a process of reflection-in-action (continuous review of strategies in the case of failure) in relation to reflection-on-action (revision of fundamental concepts supporting the failed action). This concept, largely used today in professional development of the curriculum, connects learning with its practical, professional, cultural or social contexts as well as highlights this link as indispensable to the learning process (Neumann, 2000).

In education, the term relevance typically refers to learning experiences that are either directly applicable to the personal aspirations, interests, or cultural experiences of students (personal relevance) or that are connected in some way to real-world issues, problems, and contexts (life relevance)_(Fry, Ketteridge \& Marshall, 2009). In their study, Priniski, Hecht and Harackiewicz (2018) define relevance as "a personally meaningful connection to the individual" (p. 12). They consider personal meaningfulness as a key concept to the definition, emphasizing that the term is 'personal'. In the context of this paper, we therefore define relevance as the subjective perception of an individual of the degree to which a stimulus personally connects to that individual (Priniski, Hecht \& Harackiewicz, 2018). Thus, in agreement with Priniski, Hecht and Harackiewicz, this paper takes the view that, that which is relevant should be then meaningful to the individual, hence a contextually relevant curriculum.

While the work of developing a contextually relevant curriculum is not cast on stone, Binns (2015) establishes that curriculum designers barely develop a curriculum based on prescribed guidelines; thus, it is not guaranteed that any designed curriculum is contextually relevant. This paper therefore explores principles for achieving contextual relevant curriculum based on curriculum dynamism triggered by various stakeholders and other contextual realities.

\section{AREAS OF RELEVANCE}

As described by Priniski, Hecht and Harackiewicz (2018), relevance is explained in the following example:

A student reading an assignment for English class may find it relevant if the book is about rockets and the student remembers a relatively related topic in a science class. This type of relevance is indirect, because the stimulus (e.g., the reading assignment) is not perceived to be relevant in and of itself but rather through its association to something else (e.g., an experience, a memory). (p.2)

In expressing personal relevance, Priniski et al. (2018) also point to the relevance in perception that a stimulus can be used to fulfil an important personal goal. For instance, another student reading the same English assignment might consider it relevant for its utility in developing skills in reading. Finally, they identify personal relevance on the basis of identification such as a student finding an assignment for an English class relevant since the student identified as a bookworm works on reading assignments to exercise that identity. 
Contrariwise, life relevance points to the significance on educational institutions grooming individual learners to widely participate in the dynamic societal life. This is articulated by Ouma (2006), that the knowledge acquired in institutions is transmitted to learners through a formal curriculum that comprises the subject matter taught at various levels of education in an academic calendar. In this, his study makes an assumption that as learners master the contents of a particular subject of the curriculum in school, the acquired knowledge can be relevant in everyday life (Ouma, 2006).

\section{CONTEXTUAL CURRICULUM}

A study by Bolt and Swartz (1997) described contextual learning as learning through associating of the theory studied in classroom and its application in real-life. Their study reviewed three delivery models of contextual learning: cross-disciplinary approaches, selfcontained curriculum components and integrated curriculum approaches. This has been recently supported by Schrewe et al. (2018) who explain how various contextual patterns in clinical learning environments - patients that included physical geography, health care systems, clinical and educational practices and culture- formed a contextual learning curriculum matrix. They emphasize that learners that engage in the use of this contextual matrix may influence the type of physicians they become in the real world of practice. Based on the foregoing discussion, it is therefore important to help learners to recognise the various learning opportunities, especially on different training contexts and points of view, through contextually relevant designed curricular. It is only then that the education sector can be said to achieve the purpose of contextual relevance which it is intended for. Components of context that must be considered in curriculum development and review include but are not limited to the following: 
Table 1: Components of Contextual Considerations in Curriculum Development

Curriculum checklist $\quad$ Guiding Questions

1 Area of discipline

What field of study is the curriculum developed

for? (Social sciences, humanities, sciences, or creative arts)

2 Type of programme

What type of the programme is the curriculum intended for? (Postgraduate, undergraduate diploma, certificate, secondary or primary education)

3 Scope of content coverage

What is the curriculum content or the subject matter? (Macro and micro levels)

4 Geographical location

What is the geographical location of the institutions for which the curriculum is intended? (Rural, suburb, slum, semisettlement or urban)

5 Mode of delivery How will the curriculum be delivered to the learners? (Face to face, online, correspondence, or hybrid/blended)

6 Duration of programme

How long will the programme for which the curriculum is developed take? (Semester, term, or a few days/weeks block/modular)

7 Personnel

What is the level of human capital/personnel required for the curriculum implementation? (Graduate, or post graduate)

8 Financial resources

Are the financial resources available to facilitate the design, development and implementation of the curriculum? (Sponsorship, grants, or tuition revenues)

10 Learning materials What learning materials are required in implementing the curriculum and how available are they? (Local, continental or global)

11 Facilities

What other facilities are necessary to achieving the success of the contextually designed curriculum? (Classrooms, computers, software or internship/partnership institutions)

12 Support from leaders/management Is the proposed curriculum supported by the leaders and/or top management? (Sponsor, management, senate or governing council)

13 Stakeholders expectations What are the expectations of the parents, sponsors, accrediting bodies, professional bodies among others in the curriculum being designed? (Inputs, outputs, or outcomes)

14 Similar institutions in an area/region Which other similar institutions are in the area in which the curriculum is to be used? (Programs, gaps, or resources for co-sharing)

15 Uniqueness of institution/program How unique is the institution? (Distinctiveness, or identity)

16 Culture

What is the organisational culture of the institution? (Individualized, or communal) 
17 National policies

18 Global policies
What is the vision of the country for which the curriculum is being developed? (Vision 2030, Education Action 2013, The Big 4 agenda or relevant national education and other reforms) What global trends and policies must be considered? (SDG 4 and others, African trends/reforms, or educational treaties)

The above factors must be considered in order to develop a CRC.

\section{CURRICULUM CHANGE AND REVIEW FOR CONTEXTUAL RELEVANCE}

Curricular need to be relevant at all times and for this reason, curriculum review is a necessary part of the educational management processes. There are many dynamic aspects of society that demand curriculum alignment from time to time. Curriculum review is therefore necessary to incorporate the dynamism of societies (human needs, technology and various socio-economic issues, among others) and to respond to needs' assessment and related curricular assessment and evaluation reports.

Various scholars have advanced the reasons for change in curriculum explaining what drives change. According to Lachiver and Tardif (2002) for instance, there are key factors that prompt curriculum change within a department among them; influential individuals, financial pressures, staffing issues such as workload, viewpoints of students and employers or industry, government regulations and students' abilities among others. A summary of drivers to change comparing cases in two countries, Kenya and Australia, are as shown in table 2.

Table 2: Drivers to Curriculum Change

\begin{tabular}{l|l}
\hline Kenya (Syomwene, 2016) & $\begin{array}{l}\text { Austrasia (Gruba, Paul, Alistair } \\
\text { Moffat, Harald Søndergaard, \& } \\
\text { Justin Zobel, 2004) }\end{array}$ \\
\hline $\begin{array}{l}\text { Emerging issues in the society. e.g. } \\
\text { terrorism, HIV/AIDs, Ethnicity }\end{array}$ & Influential or outspoken individuals \\
\hline $\begin{array}{l}\text { Changes in knowledge (Epistemological } \\
\text { changes). e.g. learner centered education, } \\
\text { individualized instruction, special needs } \\
\text { education and inclusive education. }\end{array}$ & $\begin{array}{l}\text { Financial pressures, including } \\
\text { resource availability }\end{array}$ \\
\hline $\begin{array}{l}\text { Global trends e.g. SDGs } \\
\text { Economic issues e.g. cost of education }\end{array}$ & Staff availability or workload \\
\hline $\begin{array}{l}\text { Changes in national educational philosophy } \\
\text { e.g. education commissions }\end{array}$ & $\begin{array}{l}\text { Current or prospective student } \\
\text { viewpoints }\end{array}$ \\
\hline Political changes e.g. new constitution & $\begin{array}{l}\text { Pedagogical argument, or academic } \\
\text { merit }\end{array}$ \\
\hline $\begin{array}{l}\text { Physical changes. e.g. environmental } \\
\text { changes in the world and locally. }\end{array}$ & $\begin{array}{l}\text { University or Government } \\
\text { requirement or regulation }\end{array}$ \\
\hline $\begin{array}{l}\text { Employment agencies. e.g. institutions and } \\
\text { industries }\end{array}$ & $\begin{array}{l}\text { Professional accreditation needs, or } \\
\text { syllabi set by professional bodies. }\end{array}$ \\
\hline & $\begin{array}{l}\text { Academic "fashion", including the } \\
\text { desire to remain in step with other } \\
\text { institutions. }\end{array}$ \\
\hline
\end{tabular}


Curriculum change may therefore be concerned with:

- The elements of curriculum (objectives, content, learning experiences and evaluation)

- Procedures of doing things and time schedules

- Alterations in school programmes, management and leadership as well as the introduction of new courses and programmes

- Classroom level, school level and in the educational system in general (Syomwene 2016, pp. 174-175)

Curriculum change should however not be done haphazardly as it has been done in various periods and contexts. Change should be out of responses to the triggers of curriculum change and requires intentionality. It should therefore be strategically planned, diligently implemented and periodically reviewed.

\section{KENYA'S CURRICULUM REFORMS AND IMPLICATIONS FOR CHRISTIAN HIGHER EDUCATION}

Kenya, like all nations concerned about thriving citizenship, has been keen to respond to contextual realities by developing, implementing and reviewing the curricular at various levels of society. In the last five years, much has been done to streamline higher education curricular nationally, after the development of the Education Act 2013, through the Commission for University Education (CUE). According to Baker and Le Tendre (2005), learning institutions are fundamental to moulding the real world through societal development. It is therefore crucial that what learners use as a curriculum is designed to match the needs of the dynamically changing environment. The Government of Kenya has been seeking to use learning institutions to strengthen citizenship values and the economy in general through a contextually relevant designed curriculum. A needs' assessment conducted by the Kenyan Institute of Curriculum Development (KICD) in the year 2016, established that the national curriculum has to meet both the dynamic needs of individual citizens and the nation as a whole, and thus resolved to adopt a competency-based approach (CBA) in the Kenya's curriculum reforms. Principally, this was also based on the focus to achieving the Sustainable Development Goals (SDGs) such as goal 4 whose aim is for citizens to achieve quality education that will result to goal 1 of poverty reduction. The competency-based approach in the Kenya's curriculum is therefore aligned to the international best practices in education systems and curriculum reforms, hence its adoption is aimed at making learning more meaningful (Njeng'ere \& Ji, 2017).

According to Njeng'ere and Ji, (2017) in a UNESCO report, the blue print for national development in Kenya as envisioned by the Kenya's Vision 2030, details need for a reformed education system in the country to equip citizens with the necessary skills, knowledge, attitudes as well as values geared towards achieving the nation's economic, social and political aspirations.The Basic Education Framework emphasizes on competence-based curriculum and its focus is aimed at facilitating the achievement of vision 2030, fulfilling the mandate of the constitution (2010) and adherence to the education act 2013. Given these reforms, institutions of higher learning must review their curriculum to match contextual demands.

A close look at the new basic education framework reveals that even though values are key pillars of the framework, it misses foundational theories for morality such as by Kolhberg (1984), Gillian (1982); and faith development theories such as Fowler's (1981). This is an opportunity for concerned constituents, such as Christian universities, to provide leadership. Moreover, Christian theology is contextual by nature and therefore the need for studies on trends in social, global, economic, and political spheres and their impact on human beliefs, values and morality, and vice versa. This prompts a need for Christian higher education 
institutions to be involved in contextual curriculum design. Theological honesty about the contextual realities that face Africa would help the church to be a public church that actively witnesses to all spheres of life about the way the truth and the life (Hendriks, 2004, p. 27). Christian institutions of higher learning therefore, have an opportunity to participate and fill the faith, values and morality gaps as provided for by the laws of Kenya.

While it is still debatable on the role played by religious institutions in the development of the education curriculum, it is for a fact that ensuring religious guided curriculum enables adequate development and implementation across the national curriculum which in turn improves religious literacy and ensures relevance in education (McKeown, 2010). Christian Institutions of higher learning can engage in the development of a school curriculum for the following purposes:

- Development of the Religious Education syllabus.

- Administration of the Programmes of Pastoral Instructions (PPIs) in primary school levels for learners in various religious groups.

- Establishment of in-service teacher education programmes for Religious Education teachers to keep them abreast with the emerging issues.

- Development of infrastructure in schools such as building of classes and provision of support materials.

- Training of teachers in various private colleges and universities that they manage.

- Developing of ethical and value-based curriculum that addresses morality in society.

To succeed in these areas, various domain of change management must be carefully considered and curriculum plan must therefore include management of change. Ideally, according to Lachiver \& Tardif (2002), quoted by Gruba et al. (2004, p. 3), curriculum change is managed in a logical five-step process:

\section{Conducting an analysis of the current offerings and context}

Before initiating any change in the curriculum, certain considerations have to be made on whether the current curriculum indeed needs to be reviewed or changed. The process of curriculum development starts from a different point for various stakeholders and the concerned institutions would want to assess the pros and cons of a new curriculum in light of a number of factors before its design (Mbarushimana \& Allida, 2017). The content and context of a curriculum is crucial and thus should address the gaps in a current curriculum and measure whether the content for the proposed curriculum meets the needs of the students contextually (National Research Council, 2004). A situational analysis is therefore necessary to establish the needs of the learners and the type of changes required in the curriculum, in this case a contextually relevant curriculum. This procedure will help in determining the resources required for the change (Mahboob \& Evans, 2015).

\section{The expression of key program aims in a mission statement}

In any programme, the mission statement plays a crucial role in guiding the teachers and learners on the right direction. During a curriculum's change, it is important to express the main aim of the programmes in a mission statement. The National Research Council (2004) notes that value judgement of whether the curriculum is fit or not, is based on the goals and objectives of the curriculum. In essence, clear SMART (specific, measurable, attainable, realistic and time-bound) objectives are required to achieve the mission goals. Bland et al. (2000) point out that a curriculum change team can seek advice from other institutions that have undergone curricular reforms. 


\section{Prioritization of resources and development strategies}

In curriculum change, mobilization of the necessary human and financial resources is fundamental (Nilakant, 2006). It should be noted that the magnitude of change expected to be made determines the amount of resource input required hence, change of a large magnitude will demand more resource inputs in terms of human resource development, planning, finances and time (Bland et al. 2000).

\section{The implementation of the targeted curricula change}

Once the idea has been developed, the next stage is now to implement the curriculum. According to Fullan (2007) the implementation stage comprises the process of putting into practice an idea, programme, or set of activities and structures new to the people attempting or expected to change" (p. 84). However, Ingram and Harris (2001) claim that the implementation stage should start after a decision to undertake change is made. Once the implementation stage is underway, the success or failure of the project relies upon the type and amount of quality assistance that is provided for the participants. The length of any implementation period varies depending on the project and the setting (Ingram \& Harris, 2001).

\section{The establishment of monitoring tools and processes}

Monitoring and Evaluation is an important stage in change management as this puts on check the curriculum to establish if the goals and objectives are being achieved.

The process will however depend on prevailing conditions for sustainable change to be achieved. Jones (2002) lists five conditions namely:

- Mutual trust amongst stake-holders- there should be agreement in ideas and trust among all the stakeholders involved in the change process.

- Committed and consistent leadership- to keep track of the designed curriculum throughout the implementations process and evaluate the whole process.

- Proceeding with a non-threatening, incremental pace of change- change is a gradual process thus following all the stages promptly will lead to a successful change management process.

- Professional development for academic staff - there is need to train the academic staff on the new curriculum so that awareness is created among all.

- The use of purposeful incentives - Incentives can be used if need be to encourage the staff on adopting to the new curriculum.

\section{CONCLUSION}

A country's prosperity is founded in its ability to grow economically, reduction in poverty and sustainable development. Education is considered a major factor that influences these achievements hence the curriculum plays a major role. A contextual curriculum is a representation of a conscious and systematic selection of skills, knowledge and values to be taught. This generally shapes the way learning, teaching and assessment processes are organised by addressing key questions as what, why, when and how students should learn. As a result, curriculum design and change should be guided by a holistic and systemic approach, which is critical to ensuring effectiveness, relevance in education and sustainability. In this process, Christian institutions of higher learning have a rare opportunity to lead the nation in coining a value-based and contextually relevant curriculum to achieve the desired society change in achieving Vision 2030 and the current government's Big Four development agenda. 


\section{References}

Baker, D., \& Le Tendre, G. K. (2005). National differences, global similarities: World culture and the future of schooling. California: Stanford University Press.

Binns, C. (2015). What can 'social practice' theory and 'socio-cultural' theory contribute to our understanding of the processes of module design? Journal of Further and Higher Education, 39(5), 758-775.

Bland, C.J., Starnaman, S., Wersal, L., Moorhead-Rosenberg, L., Zonia, S., \& Henry, R. (2000). Curricular change in medical schools: How to succeed. Acad Med 2000(75), 575-594.

Bolt, L. \& Swartz, Ne. (1997). Contextual curriculum: Getting more meaning from education.New Directions for Community Colleges, Spr 1997(97), 81-88.

Chiriswa, A. P., \& Thinguri, R. (2015). The Contribution of the Secondary School Curriculum to Peace in Kenya. Journal of Education and Practice, 6(3), 164-173.

Elearn Limited (2007). Techniques for sustainable change. In Elearn Limited (Ed.). Change management (89-117). Oxford: Pergamon Flexible Learning.

Fry, H., Ketteridge, S., \& Marshall, S. (Eds) (2009). A handbook for teaching and learning in higher education. New York: Taylor \& Francis.

Fullan, M. (2007). The new meaning of educational change. Fourth Edition. New York: Teachers College Press.

Gilligan, C. (1982). In a different voice: Psychological theory and women's development. Cambridge, MA: Harvard University Press.

Gruba, P., Alistair, M., Harald, S., \& Justin, Z. (2004). What drives curriculum change? Conference Paper. crpit.com/confpapers/CRPITV30Gruba2.pdf

Ingram, G., \& Harris, J. (2001). Delivering good youth work: A working guide to surviving and thriving. Lyme Regis: Russell House Publishing.

Hendriks, H.J. (2004). Studying congregations in Africa. Wellington: Lux Verbi.

Jones, M. T. (2002). Globalization and organizational restructuring: A strategic perspective. doi.org/10.1002/tie.10024

KICD (2013). The Kenya Institute of Curriculum Development Act, 2013. Gazette Supplement, Republic of Kenya.

Kohlberg, L. (1984). The Psychology of Moral Development: The Nature and Validity of Moral Stages (Essays on Moral Development, Volume 2). Harper \& Row

Lachiver, G., \& Tardif, J. (2002). Fostering and managing curriculum change and innovation. Conference: Frontiers in Education, 32nd Annual, Vol. 2 doi: 10.1109/FIE.2002.1158168 •

Mahboob, U. \& Evans, P. (2015). Key steps for managing changes in the curriculum. Journal of the College of Physicians and Surgeons Pakistan, 25 (2), 85-86.

McKeown, D. (2010). The role of the churches in education. Irish Catholic Bishops' Conference.

National Research Council (2004). On evaluating curricular effectiveness: Judging the quality of k-12 Mathematics evaluations. Washington DC: The National Academies Press.

Mbarushimana, N., \&Allida, D. (2017). Curriculum change and teacher participation in technical and vocational education training programs (TVET): Experiences of groupescolaireaiper Nyandungu, Rwanda. Baraton Interdisciplinary Research Journal, 7(Special Issue), 1-10.

Nilakant, S.R. (2006). Mobilising support. Change management: altering mindsets in a global context. New Delhi: Sage Publications India Pvt Ltd.

Njeng'ere, D. K., \& Ji, L. (2017). Why, what and how of competency-based curriculum reforms: The Kenyan experience. IBE-UNESCO

Ouma, W. O. (2006). School knowledge and its relevance to everyday life in rural western Kenya. Nordic Journal of African Studies 15(3), 393-405.

Ozturk, I. (2008). Financial development and economic growth: Evidence from Turkey. Applied Econometrics and International Development, 8(1), 85-98.

Pillai, S.S.W. (2015). Curriculum is a comprehensive plan for an educational/ training programme/course to offer new/improved manpower to fulfil the rising needs of a dynamic society. (Unpublished Dissertation) University of Madras, India. 
Priniski, S. J., Hecht, C., \& Harackiewicz, J. (2018).Making learning personally meaningful: A new framework for relevance research.The Journal of Experimental Education, 86(1), 11-29.

Neumann, R. K., \& Schön, D. (2000). The reflective practitioner, and the comparative failures of legal education. Clinical L. Rev.

Schrewe, B., Ellaway, R.H., Watling, C., \&Bates, J. (2018). The contextual curriculum: Learning in the matrix, learning from the matrix. Acad Med., doi: 10.1097/ACM.0000000000002345.

Smith, D., \& Ewing, R. (2002).Curriculum studies. Change: Transformations in education,5 (1), 26-45.

$\mathrm{Su}$, S.W. (2012).The various concepts of curriculum and the factors involved in curricula-making. Journal of Language Teaching and Research, 3(1), 153-158.

Syomwene, A. (2016). Change and management of change in curriculum. In Syomwene, A., Nyandusi, C., \&Yungungu, A. (Eds). Core Principles in Curriculum. Eldoret, Kenya: Utafiti Foundation.

United Nations. (2006). The Millennium Development Goals report: 2006. United Nations Development Programme, www.undp.org/publications/MDGReport2006.pdf

Yungungu, A. (2016). Curriculum development in Kenya. In Syomwene, A., Nyandusi, C., \& Yungungu, A. (Eds). Core Principles in Curriculum. Eldoret, Kenya: Utafiti Foundation. 